\title{
Rechazo sin evidencia: Prejuicio político entre jóvenes meridanos
}

\author{
Martín Echeverría Victoria* $y$ \\ Maricarmen Garay Hernández** \\ UnIVERSIDAD ANÁHUAC MAYAB
}

Una preocupación fundamental para la política mexicana es el aparente desinterés y apatía de los jóvenes hacia la participación política, sus instituciones y acontecimientos. Para abordar estos fenómenos, el trabajo aquí comentado partió de la socialización política y se concentró en las representaciones que los jóvenes tienen sobre el gobierno. Recurriendo a un diseño cualitativo consistente en grupos focales y entrevistas profundas, los hallazgos indican la reproducción de actitudes y valores de la cultura política mexicana en los jóvenes, una representación personalizada y apolítica del gobierno, y destacan el papel de la familia, uno de los pocos vínculos entre los jóvenes y el sistema político.

Palabras clave: Socialización política, jóvenes y política, mediaciones, gobierno, representaciones.

One of the foremost concerns for Mexican politics it's the current disengagement and apathy among young citizens towards political participation, institutions and events. To face these issues, a study was done based on a political socialization perspective and focused in the representations that young individuals construct about the local government. Using focus groups and in depth interviews, it was found that young Mexican citizens are reproducing the general values and attitudes from Mexican political culture, hold personalized and

\footnotetext{
* Comunicólogo; Maestro en Comunicación por la Universidad Internacional de Andalucía, Maestro en Comunicación Política por la Universitat Pompeu Fabra de Barcelona; y doctorando en Ciencias de la Información por la Universidad de Sevilla. Profesor investigador de la Universidad Anáhuac Mayab. Sus líneas de investigación son los formatos audiovisuales de la comunicación política y las representaciones mediáticas de los grupos vulnerables. Correo electrónico: echevemartin@yahoo.com.mx ** Comunicóloga y periodista; candidata a Maestra en Comunicación Institucional por el Centro Avanzado de Comunicación "Eulalio Ferrer". Correo electrónico: carmen.garay@unimayab.edu.mx
} 
depoliticized representations about government, and that family is a crucial institution that can uphold a link between the youth and the political system.

Key words: Political socialization, youth and politics, mediations, government, representations.

\section{INTRODUCCIÓN}

Es prácticamente un lugar común decir que los jóvenes en la actualidad están despolitizados, y que son apáticos e indiferentes hacia los asuntos públicos. Su integración al sistema político mediante la participación electoral o el interés por los asuntos públicos se hace cada vez más lejana, en tiempos en que las tasas de participación, vía electores o militantes partidistas, disminuyen aceleradamente, de manera que un cambio generacional positivo se torna apremiante.

En medio de las duras cifras de participación precaria que sustentan las percepciones anteriores, ${ }^{1}$ la juventud, aun en tiempos neoliberales, todavía reconoce al Estado y su institución contingente, el gobierno, interviniendo en sus vidas. Ya sea apelando a su adhesión desde el marketing de gobierno o integrándose gradualmente a los mecanismos estatales de cobertura social — créditos de vivienda, educación, salud o impuestos—, fiscal o de fuerza pública, los jóvenes, necesariamente, desarrollan una posición frente al Estado, y mediante ello, de manera mínima, al sistema político, aun para darle la espalda.

Mientras que la indiferencia a los procesos electorales o el descrédito a los partidos políticos y otras instituciones pudieran ser zonas opacas —en tanto vacíos cognitivos- al momento de profundizar en los resquicios de la conciencia cívica juvenil, creemos que las claves de comprensión de los problemas de despolitización de los jóvenes se encuentran observando la relación que éstos establecen como colectivo con el gobierno local ${ }^{2}$ y mediando entre ambos un par de elementos constitutivos internos y externos: en lo interno, los constructos políticos sedimentados por la formación cívica (democracia, valores políticos y representaciones institucionales);

\footnotetext{
${ }^{1}$ Una cifra representativa la proporciona el IFE, que afirma en un estudio realizado, que en las elecciones federales de 2003, el $70 \%$ de las personas entre 19 y 30 años no acudió a votar (Elecciones 2006 en manos de los jóvenes: IFE, 2005).

${ }^{2}$ Un gobierno local es el que se encarga de establecer una organización política y un ámbito de dominio sobre una circunscripción política y administrativa de la localidad (Ramírez, 2004).
} 
y en lo externo, la información política consumida cotidianamente a través de los medios de comunicación y las relaciones interpersonales.

Para efectos de síntesis, las relaciones posibles las condensamos en la operación de la representación: ${ }^{3}$ lo que intentamos es determinar las características de la relación de los jóvenes con el gobierno local a partir de sus representaciones acerca de la política y el gobierno mismo, influidas por las fuentes mediáticas y sociales a las que están expuestos. En atención a ello, un punto de vista importante para este trabajo es la actividad comunicativa de los jóvenes, las "dietas" mediáticas con los "nutrientes" de información política que consumen (Díaz, 2007), y lo que hacen con estos materiales simbólicos (Thompson, 1993) en lo individual y en sus contextos familiares (Orozco, 1996; Vega, 2004) para construir sus relaciones con lo político. En última instancia, se trata de regresar a las primeras preocupaciones de los estudios clásicos de socialización política ${ }^{4}$ que intentaban constatar el respaldo de niños y jóvenes a la democracia y al establishment gubernamental (Atkin, 1981; Chelius, 2004). Esto expresa cierta inquietud por observar el estado de integración de las nuevas generaciones a la democracia, en tiempos en que se percibe o se teme un riesgo de desintegración (en ese entonces fue la Segunda Guerra Mundial), inquietud palpable en nuestro tiempo bajo otras formas. En atención a esa perspectiva teórica, la juventud no se concibe aquí en términos socioculturales - en cuyo caso, en efecto, la juventud "no es más que una palabra" (Bourdieu, 1990)—, sino en términos llanamente demográficos (18 a 29 años de edad) y como un estadio psicosocial de formación cívica.

En ese sentido, la operación metodológica consiste en detenernos en un momento del desarrollo de los ciudadanos para observar cómo se integran cognitiva, afectiva y actitudinalmente ${ }^{5}$ (Krotz, 1997), al orden de lo

\footnotetext{
3 "En el contexto de la interacción comunicativa entendemos [...] como representación la nueva presentación de la cosa u objeto de referencia, luego del proceso mediacional, que añade ciertos atributos y desactiva o disminuye otros, en función de ideología, costumbre, habitus, contexto sociohistórico, entre otros [...] Por lo tanto, una representación social, incluidas las generadas por los medios, es una interpretación de la realidad que está destinada a ser interiorizada como representación personal por determinados componentes de un grupo" (Martín Serrano, 1994, p. 48).

${ }^{4}$ Definida como un proceso de desarrollo mediante el cual los individuos adquieren cogniciones, actitudes, valores y patrones de participación relacionados con el medio ambiente político, así como las identidades que se ponen en juego en dicho campo. Entre las agencias clave identificadas como transmisoras de orientaciones de generación a generación están los padres, la escuela, los pares y los medios. Esta perspectiva tiene cierto carácter normativo, porque observa estos fenómenos bajo el ideal de una ciudadanía consciente y participativa (Atkin, 1981; Chelius, 2004; Huerta et al., 2006).
} 
público-político, teniendo como eje la relación que pudieran sostener con una institución de alta visibilidad, el gobierno local, ${ }^{6}$ a través de las formas en que éste comunica y los ciudadanos lo juzgan. Los hallazgos pueden darnos pautas para entender la naturaleza y alcance de esta vinculación y el papel que juegan los medios en la configuración de dichos procesos, más que desde los efectos que producen, desde los recursos y contextos que proveen para construirla (Maigret, 2005).

\section{LOS JÓVENES FRENTE A LA INFORMACIÓN POLÍTICA}

¿Qué tan fundada es la percepción de desinterés y apatía política en los jóvenes? ¿Cómo se convalida esto desde el punto de vista de la actividad comunicativa de este grupo social, en el doble sentido de exposición y recepción? Las investigaciones empíricas previas, tanto cualitativas como cuantitativas, realizadas en México y distintos puntos de Iberoamérica, nos proporcionan un mapa inicial:

a) Los jóvenes consumen muy poca información política (Injuve, 2006; Poncela, 2003). Casi todos los estudios encontrados, tanto las encuestas oficiales como los trabajos académicos, coinciden con esta afirmación, constatada por el escaso o nulo conocimiento de parte de este grupo social acerca de coyunturas, acontecimientos, estructuras o actores políticos.

b) La televisión es el medio principal por el que se recibe información política (Díaz, 2007; Lastra, 2006; Segob, 2005). En esto coinciden tanto los estudios cuantitativos como cualitativos, y está a la par de una disminución generalizada del consumo de información política por medio de la prensa, el medio que históricamente ha generado y en el que ha transcurrido la vida política de las sociedades y que hoy es, aún, foco de atención primordial para una gran parte de la clase política (Cabello, 2006). Esto tiene repercusiones a nivel de la profundidad de la información que se recibe y de los referentes que entran en la conformación de lo público/político.

Acentuando la influencia de la televisión, la investigación demuestra que tiene una alta credibilidad en relación con otros medios, muy probablemente porque al lenguaje audiovisual se le confieran atributos de verosi-

\footnotetext{
${ }^{5}$ Estas categorías están de acuerdo con la definición clásica de Almond y Verba acerca de "cultura política", pero no se adhieren a nuestra propuesta y sirven más bien como componentes operativos de la experiencia subjetiva de la política.

${ }^{6}$ El gobierno local, en este caso, es el Gobierno del Estado de Yucatán, encabezado por Ivonne Ortega Pacheco, electa en 2007; se eligió a esta institución por ser la que aplica un presupuesto mayor en gastos de comunicación social en el estado, y la que tiene, con mayor probabilidad, más visibilidad y reconocimiento público.
} 
militud. Sin embargo, para otros grupos sociales la televisión en relación con la política, genera desconfianza, en específico cuando se le ve no como un medio tecnológico, sino como una institución con intereses y vínculos políticos manifiestos (Lozano, 2003; Orozco, 1996).

c) La exposición a contenidos de entretenimiento, particularmente de ficción, acapara la mayor cantidad de tiempo libre de las personas en detrimento de la información, en la que se incluyen acontecimientos políticos (Macassi, 2003). Consecuentemente, los contenidos de ficción pudieran estar modelando en mayor medida elementos de cultura política que tuvieran, a la postre, repercusiones en las formas de participación política de los jóvenes; algunos de estos elementos pueden ser modelos de conducta, valores y representaciones del entorno social, de sus problemáticas y de las características de los actores colectivos (Sánchez, 1996).

d) El consumo de la información política por parte de los jóvenes no provoca la implicación del receptor en los asuntos comunicados, sino más bien el distanciamiento de lo que se informa (Portillo, 2003 y 2004). Esto se revela en las afirmaciones de que la pluralidad de fuentes no se percibe como riqueza, sino que genera confusión, y de que hay un estado de escepticismo respecto a lo emitido en atención a supuestos vínculos entre las televisoras y el gobierno, que controlan en complicidad la información que llega al público (Lozano, 2003; Portillo, 2003). Esta actitud crítica parecería un hallazgo clave porque contradice posturas de largo aliento referentes a la juventud como grupo manipulable, pero el resultado más relevante es que los jóvenes descreen a priori de la información que reciben $\mathrm{y}$, por lo tanto, no se apropian de los referentes descritos en los medios.

En suma, aunque los jóvenes estarían, de hecho, interesados en algunos rasgos de la política, el consumo de información es bajo y tendría su origen en la desconfianza y en la falta de credibilidad en las instituciones (partidos y gobierno), más que en los procesos políticos o los valores y sistemas democráticos.

En términos de comunicación, este grupo consume poca información política, preferentemente por televisión y en descrédito de la escasa información a la que están expuestos, en parte por el mismo descrédito hacia el sistema político en su conjunto. Estos hechos pudieran estar en relación con las cifras de votación de los jóvenes, que han venido en decremento a cada proceso electoral.

Pero ¿qué hay de la información gubernamental, qué lecturas se hacen de la realidad política a partir de la misma y cómo contribuye a establecer representaciones cognitivas coyunturales o duraderas? El mapa anterior permite sentar coordenadas y hacer inferencias de lo que sucede con este tipo de recurso, que se vería sometido a condiciones de recepción similares. 
Nuestros resultados pudieran confirmar estos hallazgos e ir más allá para ver cómo atraviesan la relación que investigamos.

\section{APROXIMACIÓN METODOLÓGICA}

Ante la escasez de trabajos sobre el tema y la naturaleza de la investigación, la elección metodológica es claramente de corte cualitativo, por su capacidad para generar nuevas comprensiones acerca de los problemas. Y es que, precisamente, como parte de una de sus características relevantes, la investigación cualitativa "termina" sugiriendo nuevos caminos, en lugar de confirmar los presupuestos. Asimismo, tal como afirma Bertaux (1994), las observaciones cualitativas son "preteóricas": a diferencia de las operaciones estadísticas que encuentran magnitudes predefinidas, en lo cualitativo se intenta descubrir de qué se trata; busca identificar "relaciones, procesos, vínculos de causalidad, contradicciones, transferencias de sentido" (Bertaux, 1994).

Para fines de este trabajo dividimos a nuestra población en cuatro segmentos de acuerdo con el criterio de heterogeneidad en la investigación cualitativa (Álvarez, 2007), que representan a grupos que, con base en nuestra investigación exploratoria, tienen concepciones razonablemente divergentes respecto a la política. Las variables de segmentación clave fueron la edad y el nivel socioeconómico.

Y es que la edad influye en la posición de los sujetos respecto al gobierno; de los 17 a los 23 años - periodo de estudios universitarios, cuando los hay- los sujetos siguen, por lo común, insertos en el ámbito familiar. Al no tener una unidad familiar propia y no verse inmersos en responsabilidades que los vinculen con el aparato gubernamental (en lo referente a temas como impuestos, trámites, permisos, asuntos legales, etcétera), tienen más probabilidades de carecer de una concepción amplia del gobierno y sus características. Asimismo, se han incorporado recientemente al sistema político como ciudadanos plenos con derecho a votar, y su experiencia electoral apenas cuenta con un solo ejercicio, cuando mucho, lo que implica que su punto de vista se restrinja al ámbito escolar y la familia nuclear, y lo que los diferencia del segmento de jóvenes adultos ( 25 a 29 años), que con mayor probabilidad se han incorporado al ámbito laboral, han desarrollado una vida independiente del seno familiar —en su propia familia o por su cuenta—y el peso del aparato público, desde las dimensiones legales, fiscales y de servicios, se les ha manifestado con mayor fuerza. ${ }^{7}$

En cuanto al nivel socioeconómico, las implicaciones son profundas. ${ }^{8}$ En primera instancia, los grupos de nivel socioeconómico bajo son más 
dependientes del gobierno para satisfacer sus necesidades básicas mediante la entrega de apoyos o subvenciones, en temas de educación, salud, transporte o vivienda, a diferencia de los niveles socioeconómicos más altos, relativamente independientes del gobierno en los servicios básicos. También hay una sensible diferencia en cuanto a afiliaciones partidistas, terreno en el que las clases medias tradicionalmente se identifican con partidos de derecha, como el Partido Acción Nacional (PAN), y las clases populares, con partidos de centro y de izquierda, como el Partido Revolucionario Institucional (PRI) o el Partido de la Revolución Democrática (PRD) (Loaeza, 2008).

Para recolectar los datos utilizamos, para los miembros de clase media, la técnica de grupos focales, cuyo interés "consiste en captar la forma de pensar, sentir y vivir de los individuos que conforman el grupo" (Álvarez, 2007). La principal característica de los grupos simulados estriba en que el grupo es círculo y nudo. En cada grupo las comunicaciones son circulares, pura simetría, perfecta circularidad.

Para los fines de esta investigación hemos elegido realizar dos grupos focales de acuerdo con la recomendación de Mertens (Fernández et al., 2006), e incluir a ocho sujetos dentro de los grupos.

Para recolectar los datos de la clase popular, utilizamos entrevistas semiestructuradas in situ (Gaitán \& Piñuel, 1998) puesto que al convocarlos a un lugar determinado, suelen no acudir. El número de sujetos se estableció de acuerdo con el nivel de saturación del grupo, que llegó a las 12 entrevistas. Tanto los grupos focales como las entrevistas fueron realizados en la ciudad de Mérida, Yucatán, en el periodo de diciembre de 2008 a febrero de 2009.

Para el procesamiento de la información empleamos una codificación temática utilizando los enunciados como unidades de análisis (Hernández et al., 2006). Dicha codificación temática contrasta, compara y abstrae los elementos constitutivos del significado, y realiza una categorización inductiva en referencia a conceptos o temas. Lo que es relevante es la sola ocurrencia de un tema o marco dentro de la comunicación (Jensen, 2002)

De la misma manera implementamos un software que nos permitió graficar un árbol expansivo de categorías conforme fuimos agrupando los

\footnotetext{
${ }^{7}$ Esta tendencia puede ser relativizada por el incremento constante de la edad a la que los jóvenes se están integrando al mercado de trabajo, y que es un factor en sí de socialización política (Chejfec, 2005).

${ }^{8}$ En las consideraciones sobre la clase social lo manejamos desde el punto de vista socioeconómico del ingreso, por lo tanto, el nivel socioeconómico "bajo" se considera menor a tres salarios mínimos, y "medio", mayor a esta cifra.
} 
enunciados de los discursos de los participantes, en un proceso de comparación constante. De esta manera, pudimos encontrar inferencias y relaciones que no eran visibles en un inicio, pero que los racimos de ideas nos permitieron encontrar, poniendo en práctica con ello las potencialidades creativas y expansivas de los procesos de investigación cualitativa.

\section{HALLAZGOS}

A continuación se presentan algunos datos obtenidos de las técnicas, agrupados en ciertas categorías que posteriormente serán interpretadas conforme a nuestro problema de investigación.

\section{DEMOCRACIA Y PARTICIPACIÓN POLÍTICA}

Los jóvenes favorecen valores cívicos democráticos y muestran lealtad a los mismos. Las concepciones sobre la democracia y la política son nociones relativamente sólidas y bien ancladas en los léxicos juveniles.

En cuanto a los significados de la democracia, la primera vinculación propuesta fue con el tópico electoral, entendido como "decisión del pueblo", "libertad de elegir" y "respeto de la mayoría.". En general, se concentra en dos nociones. La primera alude una definición "modesta" que apunta a la facultad de elegir a las personas que estarán en el poder, lo cual implica la libertad — garantizada por el Estado— para hacerlo. En este sentido, se abundó sobre la concepción de "libertad de elegir", bifurcándose en dos acepciones: una en donde se alude a la sola acción objetiva de participar en el proceso ("pero una persona aunque no sepa leer, ejerce la democracia"), y otra centrada en una decisión consciente que va más allá de la acción ("hay mucha gente ignorante, tiene que haber política en lenguas maternas"), como condiciones diferenciables y, al mismo tiempo, irreductibles en un ejercicio democrático. Se advirtió que suele existir coerción de la elección y que la libertad "se pierde cuando hay presión".

La otra acepción de democracia se refiere a la deliberación y la decisión colectiva, aunque en este caso posee elementos de elitismo - en cierto sentido partidista—, porque no coloca a la ciudadanía en dicha deliberación. Así, para varios entrevistados la democracia y la política es la actividad partidista solamente ("Me imagino que es donde se juntan varias personas, que se juntan para proponer cosas para la ciudadanía"). ${ }^{9}$

\footnotetext{
${ }^{9}$ Sin embargo, se presentaron casos de desconocimiento del concepto, particularmente en la clase popular.
} 
De la misma manera, surgieron otras concepciones específicas de democracia más allá de contextos electorales. Por un lado, los derechos a la libertad de expresión ("debemos defender los pensamientos"; "es lo que expresan las personas libremente."); y por otro lado, y de manera particular, una utopía de inclusión ciudadana y acceso equitativo al poder. Dicho carácter utópico con el que es definida la democracia aplica también a la representación de la política y del actuar del gobierno: aunque exentos de vocabulario, se alude a valores morales (honestidad, responsabilidad), democráticos (estado de derecho, representatividad y equidad de género), así como la búsqueda del bien común.

No obstante la relativa complejidad de estas nociones, la participación e involucramiento en la política es baja. La primera forma concebida de participación son las elecciones, y en ocasiones es reconocida como la única. Al preguntar sobre la primera experiencia de votación, los jóvenes mostraron apatía por este ritual. Las credenciales de elector las obtuvieron para finalidades no cívicas que evidenciaron una motivación meramente utilitaria o pragmática, asociada a los requisitos de identificarse y demostrar mayoría de edad, generalmente con fines lúdicos ("Para pasar al antro, manejar [...] Tramitar una beca").

Su participación electoral ha sido errática en cuanto a consistencia ("no he votado ni en el de presidente, sólo una vez voté"), y extrínseca en cuanto a motivación ("Voté en el 2007, porque mi esposa me llevó, me dijo mi esposa 'vamos a votar', y pues vamos. Sólo me dijo que me acompañe y ya que estábamos allá, voté”).

El proceso se concibe como falto de interés, y el día de las elecciones el esfuerzo de participar en los procedimientos se pondera demandante, excesivo ("además me da flojera ir a votar, aquí en la Manuel —escuela primaria—, es mucha la cola").

Excepcionalmente, se hizo referencia al trámite "porque es importante" o porque "si no votas, no puedes quejarte".

Otra forma de participación, que podríamos denominar "comunicativa", se pone en clave de la responsabilidad moral de involucrarse en discusiones públicas, particularmente aquellas con intenciones de formación cívica a personas con menos elementos de juicio, ya sea a otras generaciones o a pares ("Como no tienen conocimiento como nosotros, les decimos que escuchen a personas que realmente les van a ayudar" [...] "Platico mucho con mis amigos, no saben del Peje" - Andrés Manuel López Obrador-).

Por su parte, la conversación y el comentario político ("participamos comentando a los que nos interesan"), así como el consumo activo de información, se conciben como formas de participar.

En la construcción de las valoraciones del grupo sobre la política, emanó como una categoría consistente la relativa al discurso político, 
con representaciones igualmente negativas, que se perfilaron como causa parcial de su ineficacia y del distanciamiento generacional ("El problema es que el discurso es muy viejo y complejo, es aburrido para los jóvenes").

\section{REPRESENTACIONES NEGATIVAS: CORRUPCIÓN Y DESHONESTIDAD POLÍTICAS}

En cierto sentido, las actitudes anteriores están asentadas en percepciones negativas del desempeño de los actores políticos y funcionarios, y son convalidadas por referencias y experiencias fundamentalmente de corrupción. En efecto, la mayoría de los entrevistados expresaron una equivalencia entre política y corrupción: política es "sinónimo de corrupción", toda vez que se trata de un "sistema desgastado", cuya explicación radica en la ambición de la clase política ("viene corrupción por obtener ganancias, más poder económico").

Asimismo, se afirmó que la política "surgió bien pero ya suena despectivo por los malos manejos", y se vincula con nociones de desprestigio, pues "nadie confía en un político". La corrupción tiene fundamentos vivenciales originados en los sitios de trabajo o en experiencias escolares ("Cuando estudié en la universidad lo viví. Por ejemplo, un político nos invitaba a repartir volantes y decía: 'te van a dar un puesto'. Y ahorita, ve dónde está").

Una de las críticas principales a los actores políticos que no está relacionada con la corrupción en sentido estricto pero sí con la deshonestidad, son las promesas incumplidas por los candidatos, lo cual produce descrédito generalizado ("La mayoría no gobierna bien, como debe ser, prometen cosas como todo, a veces no lo hacen, no cumplen con lo que dicen"). Sin tomar en cuenta posibles impedimentos coyunturales o estructurales por parte del gobierno para concretar promesas de campaña, estos jóvenes contrastan activamente las promesas de campaña y el déficit en su cumplimiento.

Se destaca también el conflicto como componente negativo de la política ("desacuerdos, escándalos, riesgo") y como un factor que los distancia de la información política ("siempre se están peleando").

A propósito de la representación sobre el gobierno local, las opiniones aluden igualmente a corrupción "porque lo que se programa se queda en el camino".

En cuanto a la evaluación del gobierno, se concluye que ha habido una ausencia de cambio significativo en las prácticas corruptas. Se mencionó el caso del manejo de los medios de comunicación, del que se dice hay amenazas y compra de periodistas, "como en el pasado". 
Las "desviaciones" de la presente administración local que más se mencionan son aquellas como la "meritocracia" — definida como el ascenso político con base en favores-y, de manera particular, el nepotismo - en estrecha asociación a una generación de hijos de políticos locales connotados- ("Ya se volvió familiar, es un gobierno de toda la familia, todos los primos, primas, vecinos, cuñados, ocupan los cargos del gobierno").

La representación de la política asociada a la corrupción es planteada como factor en el desencanto o apatía de los jóvenes por estos temas y sucesos. Esta posición se asume como generacional; proviene de una autorreflexión colectiva ("Por eso los jóvenes hemos bloqueado la política. Yo me entero porque trabajo en TV Azteca, pero en lo más mínimo nos atrae").

\section{CRiterios de evaluación gubernamental. Crítica y Culto}

En los jóvenes de clase media el gobierno se juzga excesivamente personalizado, y se acusa a la gobernadora de buscar únicamente proyectar su imagen. La alta visibilidad de su figura y la proyección mediática que se le ha dado produce, en consecuencia, la sensación de que "sigue en campaña". Esto significa para el grupo que una parte importante de las actividades son realizadas bajo criterios de espectacularización y dirigidas a la proyección pública del líder, en detrimento de una acción "seria" del gobierno que no parece empezar aún.

Se cree, además, que las acciones "mercadológicas" de proyección personal ocultan determinados rasgos desfavorables de la gobernadora que ahora ya están siendo visibles, tales como la falta de liderazgo en su gabinete o el alcance "real" de su elocuencia. Se cuestiona si detrás de las cualidades formales proyectadas existen cualidades sustanciales como gobernante ("Fue un producto mercadológico como en su momento fue [el ex presidente] Fox [...] Hay una imagen pero no es la verdadera. Es puro marketing, es un producto").

En su opinión, algunas acciones de gobierno sirven como acontecimientos espectaculares para llamar la atención; son eventos de realce que en realidad no resultan pertinentes ante otras necesidades más apremiantes. ("El desvío de dinero al CRIT del Teletón, el Estado no tenía que financiar eso. Sirvió para el "bluf" del Teletón, hay cosas más importantes en la agenda, pero no estamos para eso").

Finalmente, se considera que la gestión está guiada por intereses partidistas que trabajan para permanecer en el poder en cuanto llegan a él; esto da pie a la realización de determinadas acciones de alta visibilidad, de corto plazo, y alta rentabilidad política en detrimento del largo plazo. 
("En los dos sexenios he estado consciente del gobierno, pero es muy partidista, no se concentran en lo que hacen, sino en su partido").

Por su parte, la clase popular no parece tomar en cuenta las predisposiciones anteriores de corrupción, y tiende a valorar en mayor medida a la persona que al gobierno, particularmente desde el atributo de su juventud: la gobernadora es esencialmente una joven, no es una política como las demás. Así, los "apoyos" no son entregados por el gobierno, la administración pública o el Estado, sino por Ivonne Ortega. Esta es una forma de vinculación personalizada y desinstitucionalizada matizada por el carisma desplegado y el afecto que manifiestan hacia ella ("Normalmente la he visto en persona cuando está ayudando a la gente de escasos recursos, donde le está entregando máquinas de coser, herramientas a campesinos").

La "juventud" del gobierno es, ante todo, la juventud de la gobernadora; la personalización y representación del gobierno en el mandatario suele permear la valoración de toda la estructura ("Es joven —el gobierno-, porque la gobernadora no tiene ni 40 años").

Los aspectos más destacados son las obras que se han realizado hasta hoy. Se menciona a la gobernadora como el artífice de las numerosas obras y programas, tales como la educación y becas, vivienda, mujeres, empleo, y la entrega de zapatos.

Como es evidente en los ejemplos, una consideración asistencialista cruza las valoraciones y el significado de estas acciones, así como la consideración de ellos mismos como beneficiarios, y no como derechohabientes de los programas ("No estoy muy enterada de su historia, pero siempre la pasan trabajando mucho, caminando").

\section{REFERENTES DE REPRESENTACIÓN GUBERNAMENTAL. INFORMACIÓN MEDIÁTICA Y RECEPCIÓN CRÍTICA}

¿De dónde obtienen los jóvenes estas representaciones y sus insumos? En cuanto a medios de comunicación, los hábitos y regímenes de consumo de información política ciertamente son bajos, lo que confirma las predisposiciones distantes de la política. En general hay una actitud de evasión a los contenidos políticos en favor de contenidos sensacionalistas o de entretenimiento, sobre todo mediante la televisión y, en menor medida, en otros medios.

En suma, se configura un cuadro de bajo o nulo consumo de información política y seguimiento del acontecer político. De igual manera, la información política local, debido al desconocimiento de los referentes y el esfuerzo que supondría familiarizarse con ellos, tampoco se consume. En todo caso, la información sobre aspectos urbanos que afectan directa y materialmente a los 
ciudadanos, como baches o bloqueos, son los que llaman la atención - lo cual se queda en la esfera de la administración pública, que es una parte de la política-, aunque en menor medida que las noticias sensacionalistas.

Respecto a la escasa información gubernamental a la que se exponen, se invoca la fuerza de verosimilitud de la televisión para afirmar, a manera de testigo, las acciones positivas del gobierno. Es interesante también que se mencionen y valoren las consecuencias positivas a condición de que sean visibles.

Aunada a la escasez de consumo de información pública, en ninguno de los casos a los medios se les confiere absoluta credibilidad institucional ("Escucho que el gobierno ha invertido bastante en obras públicas y creo que sí es cierto porque sí ha habido muchos avances, pero no sé si todo lo que dicen es cierto hasta que vea la carretera"). Se parte de una idea más o menos clara del deber ser de la prensa. Asimismo, se destaca una deontología periodística sustentada en valores de objetividad y rigor. También se resaltan las funciones de la prensa, particularmente la función de watchdog y la representatividad ciudadana ("Siento que un periódico no debe tener una línea, deben limitarse a informar, las líneas deben venir de las opiniones. Es importante que haya una crítica al gobierno, pero que sea fundamentada"). Finalmente, el grupo consideró que el principal valor positivo del comunicador es su actitud crítica "equilibrada", como una aspiración latente de pluralidad informativa.

\section{MEdiaCiONES INSTITUCIONALES. RECEPCIÓN Y REAPROPIACIÓN DE LA INFORMACIÓN DE GOBIERNO}

De manera central, las mediaciones familiares y sociales configuran en mayor medida las representaciones de política y gobierno, provocando las adhesiones o reafirmando las predisposiciones negativas.

En las clases populares, la coincidencia de opiniones positivas entre distintos miembros de la familia, en donde no parece haber disenso o crítica, cataliza la adhesión al gobierno sin problematizar el desempeño ("Me enteré de lo del Teletón, lo habían comentado en la familia que se hacía [...] mis parientes hablan bien de ella [la gobernadora], vecinos, tíos").

La familia juega un rol importante porque es el espacio en donde se expresan las opiniones o juicios positivos, aunque mucha de la información que se comparte es de carácter sensacionalista o espectacular ("Algunos accidentes los comento, con mi esposo, con mi suegro, que se cayó el avión y eso").

Asimismo, las discusiones familiares son los principales escenarios. Éstas se suscitan con los padres, familiares o con los amigos de los padres, 
que siguen los temas contingentes de la agenda mediática ("lo más comentado es en cuanto a la preparación [de la gobernadora], fue un tema de conversación fuerte al principio, ahora no tanto"), o bien narran acontecimientos vivenciales relacionados con la administración pública.

Por su parte, las noticias televisivas se comentan con los padres, y sus evaluaciones se complementan o matizan con este tipo de experiencias de primera mano. De hecho, se reconoce que mucha de la información de la que se dispone se obtiene de las discusiones familiares. Cabe mencionar, además, que de acuerdo con el grupo, el tema político es frecuente en las conversaciones familiares; es por esto que en el segmento de clase media la representación negativa a propósito de los ámbitos político y gubernamental, no se explica por cuestiones vivenciales ni referentes mediáticos, sino mayoritariamente por la influencia preponderante de la institución familiar.

Para la clase popular el trabajo es otro espacio de comentario, sobre todo en cuanto a lo positivo, así como otros lugares públicos en donde no se entablan conversaciones, sino que se escuchan pláticas que, se cree, certifican un clima de opinión positivo hacia la gobernadora ("en el camión estás escuchando que hablen bien de ella"). Así, los comentarios con grupos secundarios también figuran como fuente de información, particularmente de aquellos que leen periódicos y que sirven como referente.

Las opiniones reverberan en la calle y en la familia, reafirman y permiten sostener las posiciones personales. En estos círculos sociales amplios y difuminados no parece haber un líder de opinión institucional que sea el eje que sostenga el discurso positivo. Existe, en cambio, un efecto multiplicador: el sujeto confirma sus posiciones con el comentario público, y lo generaliza.

\section{ConClusiones}

De los datos expuestos y en atención a los propósitos establecidos en un inicio, tenemos un cuadro más o menos definido de atributos afectivos, actitudinales y cognitivos de un determinado estadio de la socialización política, la juventud, referentes a la institución gubernamental local. Ese cuadro está compuesto por los siguientes elementos:

1. Muchos de los juicios y representaciones que los jóvenes elaboran de la política local son típicos de la cultura política mexicana, están mínimamente mediados por los medios de comunicación informativos y se relacionan de manera estrecha con las pautas de socialización institucional familiar. En ese sentido, parece haber una transferencia y reproducción de ciertas predisposiciones políticas de una generación a otra. 
Las distintas mediciones cuantitativas sobre cultura política y respaldo a la democracia (Injuve, 2006; Latinobarómetro, 2007; Segob, 2005) revelan el descrédito generalizado de los actores políticos por parte de la ciudadanía, relacionado particularmente con su ineficacia para resolver los problemas del país; no obstante, estas mediciones expresan un amplio respaldo a la democracia y sus procedimientos (Loaeza, 2008). De manera similar, en este grupo destaca una visión relativamente compleja de la democracia, que se extiende en diversas ocasiones a otro tipo de libertades públicas y de derechos: la lealtad a la democracia, el descrédito de los actores políticos y la escasa participación efectiva - típica también de la cultura política mexicana, que se define como "aspiracional" (Loaeza, 2008) - sugiere la existencia de una noción utópica de la política, que expresa inconformidad por las condiciones actuales, pero que al mismo tiempo orienta la subjetividad política (Krotz, 1997). Aquí lo destacable es que, de acuerdo con nuestros datos, estamos atestiguando la transmisión y reproducción de actitudes y valores propios de la cultura política mexicana de las últimas décadas, con diferencias importantes pero no decisivas respecto a la generación anterior.

2. En ambos grupos las representaciones del gobierno están personalizadas, desinstitucionalizadas y, en alguna medida, son dependientes de la exposición a la propaganda oficial, con orientaciones generadas por el contexto interpersonal. Como corolario, dicha personalización es favorecida por las expectativas originadas en la juventud del líder, que es carismático y concita identificación.

La sospecha de que la política se personalizaría a partir del surgimiento de la televisión se confirma aquí como un rasgo ya plenamente incorporado en las concepciones de los ciudadanos, particularmente clave para los jóvenes. La figura de la gobernadora Ivonne Ortega es emblemática de las identidades políticas construidas alrededor de liderazgos, no de ideologías o partidos; la potencia de las personalidades para definirlas se manifiesta en la clase popular en forma de una nueva y auténtica identidad colectiva que reemplaza a los ejes de identidad de generaciones previas (Verón, 1998). También, se relaciona con un cambio de valores de una política racional a una emocional.

Por otra parte, y en contraste con la clase media, que destaca la evidente teatralidad de las acciones del líder (Martín Barbero, 2001), la personalidad en las clases populares conforma seguidores y articula adhesiones basadas en el carisma. Por encima de estas diferencias, se constata la desinstitucionalización de la política como un fenómeno creciente. No implica despolitización porque, de acuerdo con ciertos autores, los intereses políticos siguen vigentes, pero ahora están ceñidos sobre causas, no sobre organizaciones 
(Chejfec, 2005), aunque definitivamente implica una transición hacia agendas de cambio focalizado, no estructural, y, en general, una transformación de la estructura de valores de la sociedad que individualiza y "empaqueta" los valores políticos a partir de los que actúa. (Dahlgren, 2000).

3. La desinstitucionalización implica que las valoraciones sobre las instituciones gubernamentales se dan a partir de las personalidades políticas y la proximidad afectiva que se tenga con ellas.

Aunque en ocasiones se realicen apreciaciones negativas de ciertas políticas o del desempeño gubernamental, la opinión que parte de la figura de la gobernadora para evaluar al gobierno suele ser acrítica. Al parecer, no se entiende la representación política en su organicidad, ni al gobernante como la cabeza de la estructura y las decisiones políticas. Esto puede ser interpretado como una consecuencia del marketing político, al erigir personalidades cuyo carisma rebasa su identificación con el aparato de gobierno; como afirma Debray (1993): la personalización se superpone a la personificación. Así, la cultura política, nutrida por una cultura mediática basada en "estrellas", separa dos ámbitos que parecen funcionar con autonomía.

4. El juicio y la actitud hacia el gobierno actual presentan una polarización de clase social.

Por parte de la clase popular existe una respuesta entusiasta hacia el asistencialismo y la personalización gubernamental, al punto de definir una identidad política alrededor de un líder, como se mencionó. La movilización pragmática de los recursos públicos, fuera de consideraciones de política pública planificada, origina una noción de gobierno fundada en el paternalismo y en la lógica de la transacción —intercambio recíproco-, mas no del derecho —otorgamiento legítimo-. Por el contrario, existe un rechazo por parte de los jóvenes de la clase media a la personalización, y se activa una memoria histórica inducida por la familia, mediante la cual se juzgan ciertas prácticas de gobierno como un "regreso al pasado", pasado que, por cierto, nunca conocieron y que nos habla de la permeabilidad que este grupo presenta en la definición de sus referentes políticos.

5. Fruto de la escasa exposición de los jóvenes a la información política, es posible afirmar que las representaciones y valores a propósito del gobierno son formados por el núcleo familiar, particularmente en los procesos de interacción en la recepción y reapropiación de la información de gobierno.

Uno de los aspectos clave de la perspectiva de socialización política es la participación de ciertas agencias en la formación cívica y el alcance y peso de cada una de ellas en la conformación de sus valores y predisposiciones políticas. Lo que observamos con nuestros datos es el peso preponderante de la familia como mediador institucional en la recepción de 
las informaciones políticas; armada de la autoridad moral que la caracteriza, es capaz de legitimar o favorecer determinadas lecturas de los medios o posiciones políticas (Orozco, 1996). Funciona también como una comunidad de interpretación que somete a reapropiaciones constantes los materiales simbólicos que los jóvenes consumen, anclando sus significados. La familia es el principal agente socializador que sostiene en gran parte la vinculación de los jóvenes al sistema político, vía el gobierno, y define muchas de las representaciones que en ellos se sedimentan.

Asimismo, observamos que el entorno social, en forma de amigos, compañeros de trabajo o simples ciudadanos de a pie, adquiere importancia al funcionar como comunidades de recepción en donde, mediante la discusión con otros sujetos, se genera un determinado significado (Vega, 2004). En este caso se confirma lo que encuentran los estudios revisados al inicio de este trabajo: el consumo de información política es mínimo, es principalmente televisivo, y es evitado de manera constante. Aunque la actitud es congruente si consideramos lo que los jóvenes nos dijeron a propósito de los políticos y de su escasa participación en la política en general. Sin embargo, lo que las cifras pueden perder de vista es el hecho de que existen otros agentes de socialización que comunican información política, principios y valores democráticos que, de una manera distinta y ciertamente lejana a la ideal, insertan al individuo en el sistema político e inscriben en él una forma particular de ciudadanía.

Por último, podemos mencionar que la vinculación con el gobierno por parte de los jóvenes presenta las siguientes características: tiene una configuración que podría pensarse despolitizada; no muestra rasgos ideológicos y referencias - informaciones- concretas y continuamente alimentadas por acontecimientos; y ocasionalmente recoge determinadas informaciones de otros entornos e instituciones sociales para hacerse un juicio, que carece de profundidad. Aún así, sostiene valores democráticos y cívicos fundamentales, y reproduce varios rasgos emblemáticos de la cultura política mexicana. En ese sentido, se pone en un camino que no es privativo de la juventud actual, y que implica el desarrollo de una conciencia cívica madura por parte de la ciudadanía mexicana, tarea aún pendiente.

\section{REFERENCIAS BIBLIOGRÁFICAS}

Álvarez, J. L. (2007). Cómo hacer investigación cualitativa. Fundamentos y metodología. México: Paidós.

Atkin, C. K. (1981). "Communication and political socialization". En D.N.K. Sanders (ed.), Handbook of Political Communication. Berverly Hills: Sage. 
Bertaux, D.B.I. (1994). El patrimonio y su linaje: transmisiones y movilidad social en cinco generaciones. Estudios sobre Culturas Contemporáneas, VI, 18, 27-56.

Bourdieu, P. (1990). Sociología y cultura. México: Cocaulta/Grijalbo.

Cabello, M. A. (2006). Los jóvenes y la prensa: hábitos de consumo y renovación de contenidos. Ámbitos, 15, 271-282.

Chejfec, S. (2005). La juventud extraviada. Entrevista a Néstor García Canclini. Nueva sociedad.

Chelius, L. C. (2004). Socialización política. En Laura Baca et al. (eds.), Léxico de la política (pp. 695-697). México: Fondo de Cultura Económica.

Dahlgren, P. (2000). Media, citizenship and civic culture. En J. Curran \& M. Gurevitch (eds.), Mass media and society. Londres: Arnold.

Debray, R. (1993). L'État séducteur. Les révolutions mediologiques du pouvoir. París: Editions Gallimard.

Díaz, B. (2007). Tendencias 07. Medios de comunicación. El escenario iberoamericano. Madrid: Ariel/Fundación Telefónica.

Elecciones 2006 en manos de los jóvenes: IFE. (2005, 5 de diciembre). $E l$ Universal.

Huerta, E. et al. (2006). El rol de la política en la socialización política de los niños: resultados preliminares. En M.A. Rebeil (ed.), XIII Anuario de Investigación de la Comunicación Coneicc. México: Universidad Anáhuac Norte/Universidad Iberoamericana León/Ciudad de México.

Gaitán, J. A. \& Piñuel, J.L. (1998). Técnicas de investigación en comunicación social. Madrid: Síntesis.

Hernández, R. et al. (2006). Metodología de la investigación (4a. ed.). México: McGraw-Hill.

Injuve. (2006). Encuesta Nacional de la Juventud 2005, resultados preliminares. México: Injuve.

Jensen, K. B. (2002). A handbook of media and communication research: Qualitative and quantitative methodologies. Londres: Routledge.

Krotz, E. (1997). La dimensión utópica en la cultura política: perspectivas antropológicas. En R. Winocur (ed.), Culturas políticas a fin de siglo (pp. 36-50). México: Flacso/JP Editor.

Lastra, M. G. (2006). Política y mundo universitario: algunos datos sobre la cultura política del alumnado en la Universidad de Cantabria. Perfiles Educativos, XXVIII, 114, 152-168.

Latinobarómetro. (2007). Informe Latinobarómetro. Recuperado el 5 de marzo de 2009, en: www.latinobarometro.org/

Loaeza, S. (2008). Entre lo posible y lo probable. La experiencia de la transición en México. México: Planeta. 
Lozano, J. C. (2003). Consumo y lectura negociadas de noticieros televisivos en Monterrey, Guadalajara y México D.F. Estudios sobre Culturas Contemporáneas, IX, 18, 43-56.

Macassi, S. (2003). Agenda pública y vivencias ciudadanas juveniles. Jóvenes, Revista de Estudios sobre Juventud, 18, 126-157.

Maigret, E. (2005). Sociología de la comunicación y los medios. Bogotá: Fondo de Cultura Económica.

Martín Barbero, J. (2001). Reconfiguraciones comunicativas de lo público. Análisis, 26.

Martín Serrano, M. (1994). La producción social de comunicación. México: Alianza Editorial.

Orozco, G. (1996). Televisión y audiencias, un enfoque cualitativo. Madrid: Ediciones de la Torre/Universidad Iberoamericana.

Poncela, A. F. (2003). Cultura politica y jóvenes en el umbral del tercer milenio. México: Instituto Mexicano de la Juventud.

Portillo, M. (2003). Juventud y política, representaciones en el discurso de los jóvenes de la ciudad de México. Jóvenes, Revista de Estudios sobre Juventud, 19, 220-245.

Portillo, M. (2004). Culturas juveniles y cultura política: la construcción de la opinión política de los jóvenes de la ciudad de México. Barcelona: Universidad Autónoma de Barcelona.

Ramírez, P. (2004). Gobierno local. En Laura Baca et al. (eds.), Léxico de la política (pp. 289-299). México: Fondo de Cultura Económica.

Sánchez, E. (1996). Cultura política y medios de difusión: educación informal y socialización. En E. Krotz (ed.), El estudio de la cultura política en México: Perspectivas disciplinarias y actores políticos. México: Conaculta/CIESAS.

Segob. (2005). Tercera Encuesta Nacional sobre Cultura Política y Prácticas Ciudadanas. México: Secretaría de Gobernación.

Thompson, J. B. (1993). Ideología y cultura moderna. Teoría crítica social en la era de la comunicación de masas. México: UAM-X.

Vega, A. (2004). Amas de casa, televisión y participación política. México. Elecciones 2003. Revista Mexicana de Ciencias Políticas y Sociales, XLVI, 190, 97-112.

Verón, E. (1998). Mediatización de lo político. En G. Gauthier et al. (eds.), Comunicación y política. Barcelona: Gedisa. 